\title{
Exploring and Validating Patient Concerns: Relation to Prescribing for Depression
}

\author{
Ronald M. Epstein, MD $D^{1,2,3}$ \\ Cleveland G. Shields, $\mathrm{PbD}^{1,2,3}$ \\ Peter Franks, $M D^{4}$ \\ Sean C. Meldrum, MS $S^{1,3}$ \\ Mitcbell Feldman, MD, MPbil ${ }^{5}$ \\ Richard L. Kravitz, MD, MSPH \\ 'Department of Family Medicine, \\ University of Rochester Medical Center, \\ Rochester, NY \\ ${ }^{2}$ Department of Psychiatry, University of \\ Rochester Medical Center, Rochester, NY \\ ${ }^{3}$ Rochester Center to Improve Communica- \\ tion in Health Care, Rochester, NY \\ ${ }^{4}$ Division of General Medicine, Department \\ of Internal Medicine and Center for Health \\ Services Research in Primary Care, UC \\ Davis School of Medicine, Sacramento, Calif \\ ${ }^{5}$ Department of Medicine, University of Cal- \\ ifornia, San Francisco, San Francisco, Calif
}

Conflicts of interest: none reported

\section{CORRESPONDING AUTHOR}

Ronald M. Epstein, MD

University of Rochester Medical Center 1381 South Ave

Rochester, NY 14610

Ronald_Epstein@urmc.rochester.edu

\begin{abstract}
PURPOSE This study examined moderating effects of physician communication behaviors on relationships between patient requests for antidepressant medications and subsequent prescribing.

METHODS We conducted a secondary analysis of a randomized trial. Primary care physicians $(N=152)$ each had 1 or 2 unannounced visits from standardized patients portraying the role of major depression or adjustment disorder. Each standardized patient made brand-specific, general, or no requests for antidepressants. We coded covert visit audio recordings for physicians' exploration and validation of patient concerns (EVC). Effects of communication on prescribing (the main outcome) were evaluated using logistic regression analysis, accounting for clustering and for site, physician, and visit characteristics, and stratified by request type and standardized patient role.
\end{abstract}

RESULTS In the absence of requests, high-EVC visits were associated with higher rates of prescribing of antidepressants for major depression. In low-EVC visits, prescribing was driven by patient requests (adjusted odds ratio [AOR] for request vs no request $=43.54,95 \%$ confidence interval $[C I], 1.69-1,120.87 ; P \leq .005)$, not clinical indications (AOR for depression vs adjustment disorder $=1.82$; $95 \% \mathrm{Cl}, 0.33-9.89 ; P=N S)$. In contrast, in high-EVC visits, prescribing was driven equally by requests ( $\mathrm{AOR}=4.02 ; 95 \% \mathrm{Cl}, 1.67-9.68 ; P \leq .005)$ and clinical indications ( $\mathrm{AOR}=4.70 ; 95 \% \mathrm{Cl}, 2.18-10.16 ; \mathrm{P} \leq .005)$. More thorough history taking of depression symptoms did not mediate these results.

CONCLUSIONS Quality of care for depression is improved when patients participate more actively in the encounter and when physicians explore and validate patient concerns. Communication interventions to improve quality of care should target both physician and patient communication behaviors. Cognitive mechanisms that link patient requests and EVC to quality of care warrant further study.

Ann Fam Med 2007;5:21-28. DOI: 10.1370/afm.621.

\section{INTRODUCTION}

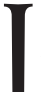
n primary care settings, some patients with major depression who would benefit from antidepressants do not receive medications,

whereas others with questionable indications do. ${ }^{1}$ We recently reported that when patients request an antidepressant medication, prescribing increases regardless of clinical indications. ${ }^{1}$ Because depression is common $^{2}$ and associated with considerable morbidity and cost ${ }^{3-6}$ and because treatment is effective,, 8 these findings have important health and quality of care implications. Patterns of underuse and overuse of medical interventions have been noted for other conditions as well. . $^{912}$

Poorly understood communication factors appear to underlie the variability in use of antidepressants. We undertook this analysis to gain understanding of the relationship between patient-physician communication and concurrent prescribing decisions. In particular, we were interested in the process of communication, rather than just the content. One feature of patient-centered communication is basing treatment on an in-depth under- 
standing of the patient's symptoms, feelings, ideas, and expectations, ${ }^{13-15}$ achieved by exploring and validating patients' concerns (EVC). When patients influence patient-physician communication through questions, assertive statements, and requests, ${ }^{16}$ ideally, they can prompt physicians to explore the patient's concerns and emotions in greater depth, correct misinformation, and make prescribing decisions that are more judicious and informed. Conversely, taking the patient's request at face value or prematurely terminating an encounter to avoid dealing with uncertainty ${ }^{17}$ would tend to favor acquiescence to the patient's request, whether or not the medication was indicated.

In the present analysis, we examined how the degree to which physicians explored and validated patients' concerns was associated with prescribing of antidepressants in a situation where these medications were clearly indicated (major depression), in a situation in which the indication was questionable (adjustment disorder), and in both situations, with and without a patient request for medication. We hypothesized that compared with visits with lower levels of EVC, those with higher levels of EVC would be associated with (1) higher rates of prescribing for major depression for patients not making requests and (2) lower rates of prescribing for adjustment disorder for patients making requests (ie, avoidance of potential overtreatment). We also explored whether links between communication and prescribing were mediated by the number of depression-specific questions asked by the physician during the encounter, and whether EVC had effects on mental health referrals and follow-up planning.

\section{METHODS}

\section{Design Overview}

This study tested a secondary, a priori hypothesis within a randomized controlled trial (Figure 1). The trial used standardized patients to portray 2 clinical conditions (major depression and adjustment disorder) and 3 types of requests for antidepressants (brand-specific, general, or none) (Table 1). The main objective of the parent study was to examine the effect of patient requests on the prescribing of antidepressant medications. With physicians' prior consent, standardized patients were introduced covertly into the practices of 152 primary care physicians in 3 cities in 2003-2004. Visits were surreptitiously audio recorded and analyzed. The protocol was approved by institutional review boards at all participating institutions and has previously been described in detail. ${ }^{1}$

\section{Sample of Physicians}

A random sample of general internists and family physicians in Sacramento, Calif, San Francisco, Calif, and Rochester, NY, were recruited by telephone and mail (Table 2). Physicians were told that the study would involve seeing 2 standardized patients over the next few months to "assess social influences on practice and the competing demands of primary care." Physicians received $\$ 175$ plus $\$ 100$ per office visit.

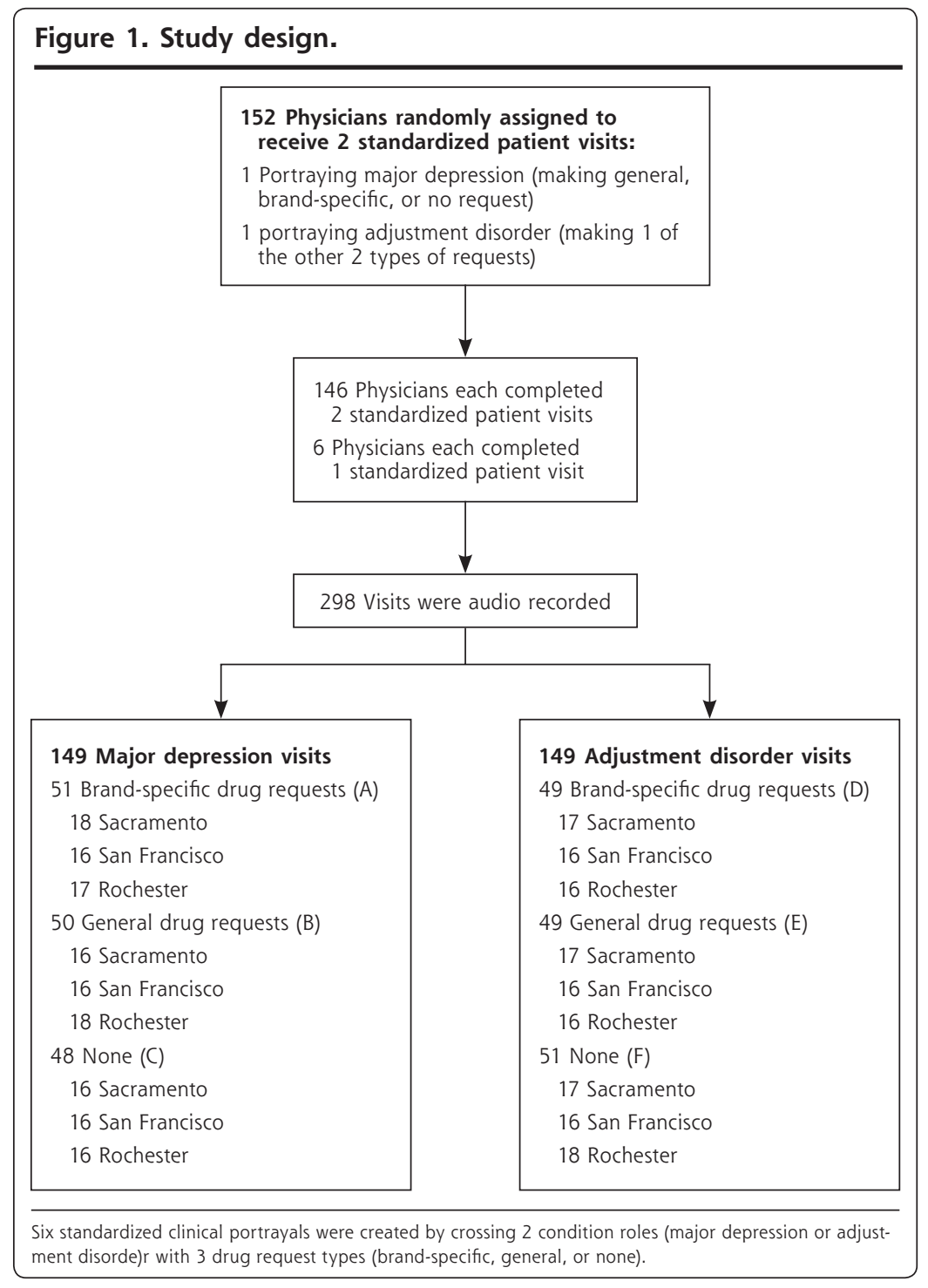




\section{Role Development}

Detailed clinical biographies were developed by the investigators and a multidisciplinary Scientific Advisory Committee, and were revised until they were judged to be realistic and manageable in a 15 -minute new-patient acute visit. The major depression and wrist pain role was an otherwise healthy 48-year-old woman reporting worsening depression over 1 month, anhedonia, low energy, trouble concentrating, sensitivity to criticism, poor appetite, and early morning awakening, but no suicidality. The adjustment disorder and low back pain role was a 45 -year-old woman who accepted a voluntary layoff rather than relocate. She reported fatigue and difficulty falling asleep 3 to 4 nights per week, but no early morning awakening. (Detailed outlines of these roles are available from the authors on request.)

Actors playing both roles were further trained to make a request for Paxil in response to a television advertisement, a similar request for "medication" in response to an informational television special on depression, or no request. The standardized patients were nonobese white women, most with professional acting experience. They were trained intensively and were monitored throughout data collection using audiotape review and behavioral checklists.

\section{Conduct of Visits and Collection of Data}

Physicians were randomly assigned to standardized patients by role and type of request. Clinic personnel were told that the patient wished to become established as a "new patient" with the doctor but also had an acute issue (fatigue and musculoskeletal pain) that required attention within 1 to 2 weeks. The standardized patient made an appointment as if she were a real patient, using a false name, a plausible local address, factitious insurance identification cards, and a cell phone number that was always set to voice mail. We worked closely with a local insurer and practice managers to ensure that physicians, even in practices that were closed to new patients, would not know the identity of the standardized patient or when she would appear.

Standardized patients recorded all visits using an audio recorder concealed in a handbag. Prescribing was determined by review of prescriptions and medication samples. Because heterocyclic antidepressants can also be used to treat insomnia or pain, our threshold for determining that a prescription for one

\begin{tabular}{lc} 
Table 2. Characteristics of Participating Physicians \\
\hline Characteristic & $\begin{array}{c}\text { Mean (SD; Range) } \\
\text { or No. (\%) }\end{array}$ \\
\hline Age, years & $46.2(9.9 ; 30-81)$ \\
Time in practice, years & $17.4(9.6 ; 4-49)$ \\
Sex & \\
Male & $101(67.8)$ \\
Female & $48(32.2)$ \\
Specialty & \\
Family physician & $49(32.7)$ \\
Internal medicine & $101(67.3)$ \\
Type of practice & \\
HMO & $33(22.1)$ \\
Group & $61(40.9)$ \\
Solo & $37(24.8)$ \\
Academic & $18(12.1)$ \\
Study site & \\
Sacramento, Calif & $51(34.2)$ \\
Rochester, NY & $48(32.2)$ \\
San Francisco, Calif & $50(33.6)$ \\
Race/ethnicity & \\
African American & $3(2.0)$ \\
Asian/Pacific Islander & $32(21.3)$ \\
Hispanic/Latino & $5(3.3)$ \\
Other & $4(2.7)$ \\
White & $105(70.0)$ \\
Missing & $1(0.7)$ \\
\hline
\end{tabular}

$\mathrm{HMO}=$ health maintenance organization

Note: $\mathrm{N}=152$, but numbers of physicians do not total 152 because of missing data.

of these medications was given for depression was that the prescribed dose was at least the equivalent of $75 \mathrm{mg} / \mathrm{d}$ of amitriptyline.

Within 2 weeks of a standardized patient visit, physicians were sent a facsimile to inquire whether they suspected that one of their patients was a standardized patient. In $12.8 \%$ of encounters, physicians responded that they had been "definitely" or "probably" suspicious before or during the visit. 


\section{Measures of Communication}

We coded transcripts of the audio recordings of the standardized patient visits using a measure of EVC. The EVC measure is an adaptation for standardized patient portrayals of component 1 of the Measure of Patient-Centered Communication (MPCC) ${ }_{1}^{18}$ which has been positively correlated with patient trust ${ }^{19}$ and patient perceptions of their physicians' communication behaviors. ${ }^{20}$ To code EVC, we used the method described by Brown et $\mathrm{al}^{18}$ for component 1 of their scale. For each statement about symptoms, ideas, expectations, feelings, or daily functioning, coders assign higher scores if the physician explores the patient's concern in greater depth, validates that concern by using a statement expressing empathy, legitimation, or respect, or does both. Conversely, coders assign lower scores if the physician cuts off the discussion by changing the topic, with no subsequent consideration of that concern. Examples of typical responses are given in Table 3. Scores are normalized to range from 0 (no exploration or validation) to 1 (each concern explored fully and validated); the authors' coding manual provides detailed descriptions of the coding process. ${ }^{18}$

Two coders with a background in social work and prior experience as standardized patients and blinded to the study hypotheses were trained by the developers of the scale to score the audio recordings using the MPCC. For reliability, both coders coded the first $10 \%$ of recordings and then an additional, randomly selected $10 \%$ of recordings; ultimately, each coder coded $60 \%$ of the recordings. All visits were discussed at weekly coding meetings, and coding dilemmas were clarified. Our reliability
Table 3. Examples of Statements Coded as Cutoff, Preliminary Exploration, Further Exploration, and Validation

\begin{tabular}{|c|c|}
\hline Transcript & Coding of the Statement \\
\hline \multicolumn{2}{|l|}{ Physician-patient sequences with low EVC score } \\
\hline \multicolumn{2}{|l|}{ Back pain } \\
\hline \multicolumn{2}{|l|}{ Dr: So, what brings you in today? } \\
\hline Pt: My back has been bothering me. & Patient expresses a concern \\
\hline Dr: What kind of work do you do? & $\begin{array}{l}\text { Coded as Cutoff: physician does not respond } \\
\text { to the concern and changes the topic }\end{array}$ \\
\hline $\begin{array}{l}\text { Pt: Um, well, I was an administrative assis- } \\
\text { tant as of the beginning of January, but I } \\
\text { got laid off, so ... }\end{array}$ & Patient expresses another concern \\
\hline Dr: So, recently laid off. & $\begin{array}{l}\text { Coded as Preliminary Exploration: missed } \\
\text { an opportunity to validate the patient's } \\
\text { concerns }\end{array}$ \\
\hline \multicolumn{2}{|l|}{ Pt: Yes. } \\
\hline $\begin{array}{l}\text { Dr: Okay. Okay. And when was your last } \\
\text { physical exam, like pelvic exam, breast } \\
\text { exam, all that? }\end{array}$ & $\begin{array}{l}\text { Not coded: physician again redirects the } \\
\text { conversation, thus response is not scored as } \\
\text { Further Exploration; Cutoff coded only once } \\
\text { for each patient concern }\end{array}$ \\
\hline \multicolumn{2}{|l|}{ Mood } \\
\hline Pt: I've been feeling tired all the time. & Patient expresses a concern \\
\hline Dr: How's your sleep? & $\begin{array}{l}\text { Not coded yet: no acknowledgment or explo- } \\
\text { ration of patient's experience of tiredness, } \\
\text { but asks about a possible cause of tiredness }\end{array}$ \\
\hline \multicolumn{2}{|l|}{ Pt: I can't fall asleep. } \\
\hline Dr: Do you cry very much? & $\begin{array}{l}\text { Coded as Cutoff: cuts off patient and switches } \\
\text { topic to something related in the physician's } \\
\text { mind, but not necessarily to the patient }\end{array}$ \\
\hline \multicolumn{2}{|l|}{ Pt: Once in a while. } \\
\hline Dr: Do you feel hopeless? & $\begin{array}{l}\text { Does not explore patient's concerns and } \\
\text { switches topics; Cutoff coded only once for } \\
\text { each patient concern }\end{array}$ \\
\hline
\end{tabular}

Physician-patient sequences with high EVC score

Back pain

Dr: So, what brings you in today?

Pt: My back has been bothering me.

Dr: How so?

Pt: When I bend over it hurts, and I'm stiff in the morning.

Dr: Do you remember when it started?

Pt: Yes. I was moving boxes in my house. Dr: What did it feel like when it started hurting?

Pt: It didn't start hurting until the next day. Dr: Back pain is pretty annoying, isn't it?

Pt: It sure is.

Mood

Pt: I got laid off when my company moved. Dr: Oh, I'm sorry to hear that.

Pt: I could have moved with the company and continued my job, but I didn't want to move.

Dr: That must have been a difficult decision for you.

Pt: It was, I sometimes wonder if I made the right choice.

Patient states a concern

Coded as Preliminary Exploration

Describes in more detail

Coded as Further Exploration of the patient's concerns

Gives more information

More exploration; Further Exploration coded only once for each patient concern

Gives more information

Coded as Validation: validates patient's concerns by speaking to her underlying emotions

Patient expresses a concern

Coded as Validation because of expressed empathy

Expresses more concern

Again, validates the patient's experience, but Validation coded only once for each patient concern

Reveals more information 
data as well as means and standard deviations of the scores were virtually identical to those reported by the developers. ${ }^{18}$

\section{Analyses}

Our key analyses sought to examine whether EVC moderated the effects of patient request and patient diagnosis on the prescribing of antidepressants. We therefore included interaction terms in a logistic regression analysis to test for moderating effects. We used a random intercept logistic regression analysis to control for the clustering of standardized patients within physicians and included the independent variables of standardized patient clinical role (major depression or adjustment disorder), request type (brand-specific, general, none), EVC score, and 2 interaction terms: EVC score by role and EVC score by request type. The dependent variable was prescribing of an antidepressant. Covariates included were age and study site (Rochester, San Francisco, or Sacramento) of the physicians. Physician sex was dropped from the models reported here because it was not significantly associated with prescribing.

In addition, we also examined whether EVC moderated the effects of patient request and patient diagnosis on mental health referrals and whether physicians scheduled follow-up visits within 2 weeks.

To examine the interaction effects further, we repeated the logistic regression analyses without including the EVC term, but stratified by terciles of EVC score. Analyses were repeated examining all 3 terciles separately and all 3 request types separately. Results for the middle and upper EVC terciles were nearly identical, so they were combined. The brandspecific and general request groups were also combined, as they produced similar effects. We also conducted a mixed model linear regression analysis, with physicians as the random effect and the EVC score as the dependent variable. This analysis enabled calculation of the physician variance component, and $\rho$ is a correlation measure of the physicians' EVC performance with the 2 standardized patients. We used SAS version 9.1 (SAS
Institute, Cary, NC) and STATA 9.1 (Stata Corp, College Station, Tex) to conduct the analyses.

\section{RESULTS}

Of 341 physicians contacted, 160 (47\%) provided informed consent to participate, 146 received visits by 2 standardized patients, 6 moved or retired after a visit by 1 standardized patient, and 8 moved or retired before any standardized patient visits. Twenty recordings could not be used because of technical problems, leaving 278 useable recordings. Age and sex distributions of the 152 participating physicians (Table 2) were similar to those of nonparticipants.

\section{Prescribing}

Figure 2 illustrates graphically the differences in prescribing by EVC level, by request (yes vs no), and by clinical presentation (major depression vs adjustment disorder). In the absence of a request for medication, highEVC visits vs low-EVC visits more frequently resulted in a prescription when the patient had major depression (35.7\% vs $5.8 \%$ ). The pattern was similar when the patient had adjustment disorder $(10.5 \%$ vs $0 \%)$.

In adjusted analyses, patient requests (whether brand-specific or general) resulted in a significantly higher probability of antidepressant prescribing. Physicians were more likely to prescribe for the depression
Figure 2. Patients' receipt of prescriptions for antidepressant medications by clinical role, EVC score, and request condition.

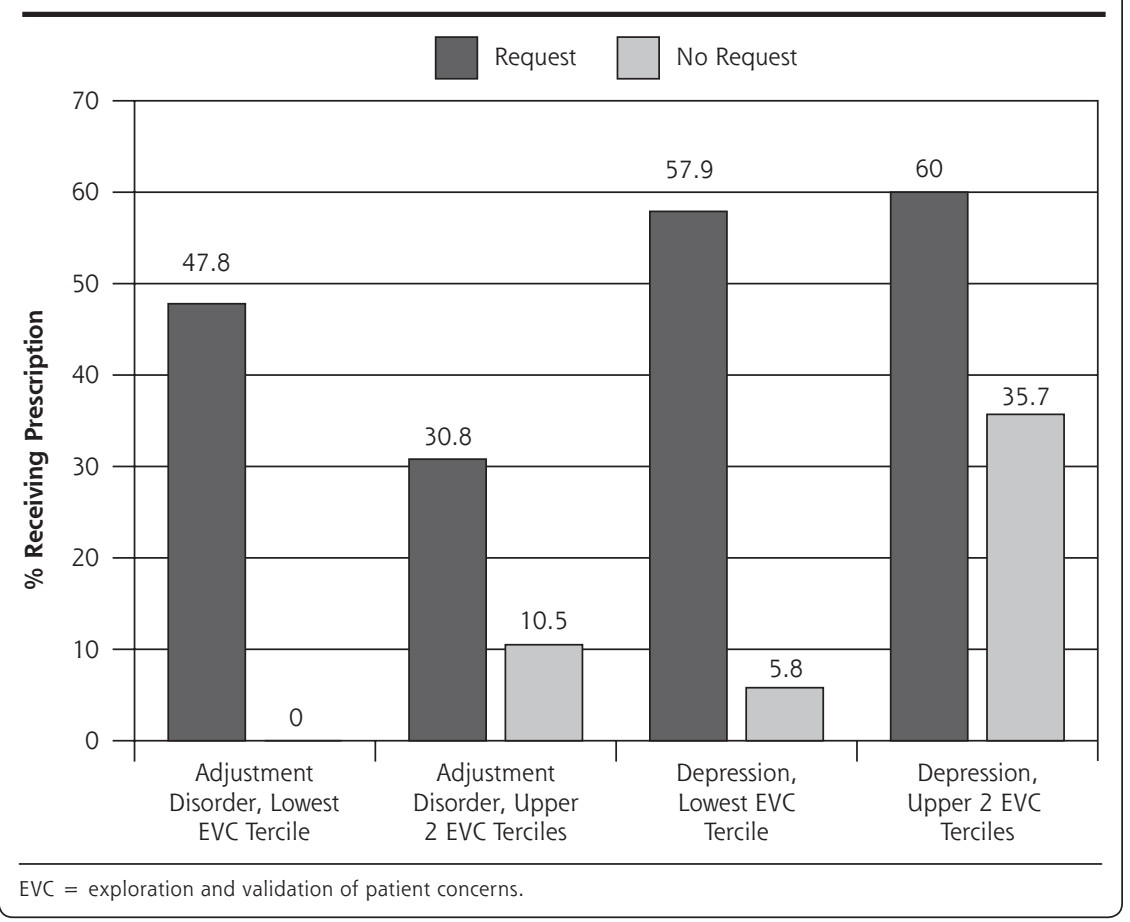


role than for the adjustment disorder role. Considering all 3 standardized patient request conditions and both roles, EVC scores were only marginally associated with increased prescribing. As suggested by Figure 2, however, we found a marginally significant interaction between EVC and request type (adjusted odds ratio $[\mathrm{AOR}]=1.07 ; 95 \%$ confidence interval $[\mathrm{CI}], 0.99-1.15$; $P<.10)$ and a significant interaction between EVC and clinical role $(\mathrm{AOR}=0.86 ; 95 \% \mathrm{CI}, 0.77-0.97 ; \mathrm{P} \leq .05)$.

To examine these interaction effects further, we stratified EVC scores by terciles and performed separate logistic regressions for each tercile of EVC (Table 4). In the lowest EVC tercile, physician prescribing was largely driven by whether the patient made any request (vs no request) $(\mathrm{AOR}=43.54 ; 95 \% \mathrm{CI}$, 1.69-1,120.87); prescribing did not otherwise differ markedly between the depression role and the adjustment disorder role. In contrast, in the upper 2 EVC terciles, prescribing was driven equally by whether the patient had depression (vs adjustment disorder) (AOR $=4.70 ; 95 \% \mathrm{CI}, 2.18-10.16)$ and whether the standardized patient made any request for medication (AOR $=4.02 ; 95 \% \mathrm{CI}, 1.67-9.68)$. Analyses examining all 3 terciles separately and all 3 request types separately produced similar results (not shown).

\section{Mental Health Referrals and 2-Week Follow-Up}

In adjusted analyses, there were no significant interaction effects for patients' requests or standardized patient roles with EVC on mental health referrals. In adjusted analyses controlling for prescribing, neither request nor clinical role was significantly associated with the likelihood that physicians would schedule a 2 -week follow-up visit.

In further analyses, we found no significant effects of the number of depression-specific questions asked or the duration of the visit on the findings presented (not shown). Physician EVC behavior was not significantly correlated across the 2 visits $(\rho=0.012, P=.37)$.

\section{DISCUSSION}

In encounters with high levels of EVC, antidepressants were prescribed more appropriately_at a higher rate when the patient had symptoms of major depression, albeit with a modestly higher rate of prescribing in adjustment disorder as well. In low-EVC visits, when patients requested antidepressant medications, prescribing was almost completely driven by patients' requests the clinical presentation had virtually no effect on the decision to prescribe. In these visits, few patients who did not request medications received them and more than one half of the patients who did request them received a prescription regardless of the symptoms they

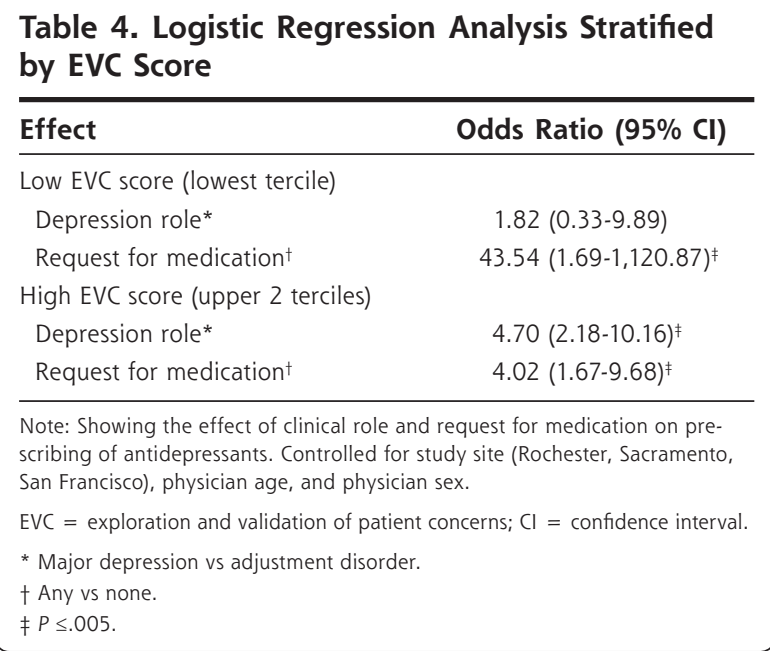

reported. In contrast, in high-EVC visits, prescribing was based to a much greater degree on the clinical presentation. These associations were observed for the communication process during the encounter, not simply due to the content (number of depression-related questions). Management of major depression also involves referral to mental health specialists and close follow-up however, EVC appeared to have no effect on rates of referral and follow-up visits within 2 weeks.

Previous reports suggest that patients can induce patient-centered behaviors in physicians when patients participate actively in the consultation (including making requests ${ }^{21,22}$; our study adds that patient requests can also influence physicians' therapeutic actions-for better and for worse. ${ }^{1}$ Our current analyses suggest that participatory patient communication behaviors are more likely to have a beneficial effect on quality of care when the physician meets that activated behavior with inquiry, openness, empathy, and validation, rather than cutoffs and assertion of his or her agenda.

From a policy perspective, this study provides additional evidence that communication can affect quality of care for depression and suggests that communication interventions to improve quality of care should target both patients' and physicians' communication skills. The stimulus for patient activation must also be considered; compared with direct-to-consumer advertisements, higher-quality sources of information may result in more requests for needed rather than unnecessary treatments.

Further research is needed to characterize the cognitive links between EVC and prescribing behavior. Studies of diagnostic reasoning reveal that expert clinicians rely on complex contextualized heuristics that guide treatment and improve the efficiency of decision making. ${ }^{23-25}$ Patient requests may trigger these scripts and, when unexamined, may result in inappropriate decision making. These cognitive processes are affected by 
contextual factors, such as physician fatigue, anxiety, or uncertainty, or busy clinic schedules, ${ }^{17,26,27}$ which may conspire to drive physicians to close visits prematurely by providing a prescription. Conversely, physicians who value consideration of patients' psychological issues and greater partnership in clinical care ${ }^{28,29}$ may be more attuned and responsive to patients' concerns and signs and symptoms of depression; they may also tend to engage in mindful examinations of their own scripts and tendencies toward premature closure. ${ }^{27}$ The final common pathway may be achievement of an attentive, nonanxious state with a fuller understanding of the patient's experience, ${ }^{14,15,30}$ leading to more informed prescribing.

We incidentally noted the lack of consistency in each physician's reactions to 2 quite similar standardized patient roles. The variability in physicians' responses to patients and their requests are likely due to time pressures, ${ }^{31}$ illness severity, ${ }^{32}$ physicians' liking of the patient, ${ }^{33}$ perceived patient trust ${ }_{,}^{19}$ and patient activation, ${ }^{21}$ all of which may affect communication, particularly physicians' comfort in refusing a request without jeopardizing the patient-physician relationship. ${ }^{34}$ These findings, though, contrast with a literature that suggests that physicians have relatively stable communication styles. ${ }^{35}$ Perhaps standardized patients, who portray first visits and are trained not to change their communication styles with different physicians, may not provide the reinforcement of physicians' communication styles seen with real patients.

\section{Strengths of the Study}

Strengths of the study are its randomized design, excellent fidelity of the standardized patient roles, monitoring, blinding, and success in avoiding detection. Even though the study was intrusive, we had good enrollment with few dropouts. By using nearly identical role presentations, we eliminated many of the sources of unmeasured variance in communication research. We conducted the study in 3 culturally distinct cities within different practice organizations.

\section{Limitations of the Study}

We view these findings as preliminary, requiring further confirmation in other patient populations, contexts, and clinical scenarios. The standardized patient roles introduced only 2 of countless patient presentations. Standardized patients portrayed first visits, which are different from visits with established patients. ${ }^{36,37}$ Findings from female, white, middle-class, middle-aged standardized patients cannot be extrapolated to other populations. We cannot determine whether direct-to-consumer advertisements provoke the behaviors portrayed by the standardized patients. Although, in theory, standardized patient detection might influence results, ${ }^{38}$ our detection rate was low, and adjusting for detection had no effect on the results reported. Our small sample of only 2 patients per physician may have contributed to our inability to detect a consistent physician style across standardized patient visits. Generalizability to nonparticipating physicians, who may be more reluctant to subject their clinical skills to scrutiny, and physicians from other regions and in settings less penetrated by managed care may be limited.

In conclusion, physician exploration and validation of patient concerns (EVC) - including the patient's symptoms, ideas, expectations, functioning, and feelings - is linked to quality of care for depression. Higher levels of EVC are associated with higher rates of prescribing of antidepressants for patients who will likely benefit from them, and with an attenuated effect of patient requests on prescribing behavior, lowering the likelihood that patients will get medication that is not clearly indicated. As far as we know, this is the first published study to link particular physician communication behaviors with appropriateness of prescribing.

Communication behaviors can be changed, ${ }^{39,40}$ even among experienced practitioners. Although patients historically have been passive in discussions about medications, ${ }^{41,42}$ the Internet, direct-to-consumer advertising, and increased patient health literacy will likely further increase patient requests. In theory, improved patient knowledge coupled with interventions that activate patients and train physicians to respond with exploration and validation might improve quality of care and outcomes for depression and other illnesses. It will be important, furthermore, to know whether physicians' responses to patient requests vary according to patients' race/ethnicity, sex, and literacy, and whether understanding those differences might help address some of the disparities in mental health care and outcomes. ${ }^{43}$

To read or post commentaries in response to this article, see it online at http://www.annfammed.org/cgi/current/full/5/1/21.

Key words: Physician-patient relations; patient-centered care; advertising; antidepressive agents; physician's practice patterns; prescriptions, drug; adjustment disorders; depression; family practice; mass media; patients; primary care; quality of health care; standardized patients

Submitted December 2, 2005; submitted, revised, April 25, 2006; accepted May 22, 2006.

Funding support: The study was supported by grant 5 R01 MH06468303 from the National Institute of Mental Health, R.L. Kravitz, Principal Investigator.

Acknowledgments: We are grateful to the following individuals who made this project possible: Debbie Sigal, Arthur Brown, Alison Venuti, Kit Miller, Lesley Sept, Jun Song, Sheila Krishnan, Wayne Katon, MD, Patricia Carney, PhD, Edward Callahan, PhD, Fiona Wilson, MD, Debra Roter, PhD, Steven Kelly-Reif, MD, Jeff Rideout, MD, Robert Bell, PhD, Debra Gage, and Phil Raimondi, MD. Special thanks are due to Blue 
Shield of California; the University of California, Davis; Primary Care Network; Western Health Advantage, Sacramento; Kaiser Permanente, Sacramento; Brown \& Toland IPA, San Francisco; Preferred Care, Rochester; and Excellus BlueCross BlueShield, Rochester. We are also indebted to 18 superb actors and to participating physicians and their office staffs.

\section{References}

1. Kravitz RL, Epstein RM, Feldman MD, et al. Influence of patients' requests for direct-to-consumer advertised antidepressants: a randomized controlled trial. JAMA. 2005;293(16):1995-2002.

2. Rush A, Hall G. Depression in primary care: Clinical practice guideline. Agency for Health Care Policy and Research; 1993. AHCPR Publication No. 93-0550.

3. Hays RD, Wells KB, Sherbourne CD, Rogers W, Spritzer K. Functioning and well-being outcomes of patients with depression compared with chronic general medical illnesses. Arch Gen Psychiatry. 1995;52(1):11-19.

4. Wells KB, Stewart A, Hays RD, et al. The functioning and well-being of depressed patients. Results from the Medical Outcomes Study. JAMA. 1989;262(7):914-919.

5. Broadhead WE, Blazer DG, George LK, Tse CK. Depression, disability days, and days lost from work in a prospective epidemiologic survey. JAMA. 1990;264(19):2524-2528.

6. Zhang M, Rost KM, Fortney JC, Smith GR. A community study of depression treatment and employment earnings. Psychiatr Serv. 1999;50(9):1209-1213.

7. Katon W, Von Korff M, Lin E, et al. Collaborative management to achieve treatment guidelines. Impact on depression in primary care. JAMA. 1995;273(13):1026-1031.

8. Simon GE. Evidence review: efficacy and effectiveness of antidepressant treatment in primary care. Gen Hosp Psychiatry. 2002;24(4):213-224.

9. Seematter-Bagnoud L, Vader JP, Wietlisbach V, et al. Overuse and underuse of diagnostic upper gastrointestinal endoscopy in various clinical settings. Int J Qual Health Care. 1999;11(4):301-308.

10. McGlynn EA, Asch SM, Adams J, et al. The quality of health care delivered to adults in the United States. N Engl J Med. 2003;348(26):2635-2645.

11. Laouri M, Kravitz RL, French WJ, et al. Underuse of coronary revascularization procedures: application of a clinical method. J Am Coll Cardiol. 1997;29(5):891-897.

12. Brook RH, Chassin MR, Fink A, et al. A method for the detailed assessment of the appropriateness of medical technologies. Int J Technol Assess Health Care. 1986;2(1):53-63.

13. Epstein RM, Franks P, Fiscella K, et al. Measuring patient-centered communication in patient-physician consultations: theoretical and practical issues. Soc Sci Med. 2005;61(7):1516-1528.

14. Stewart M. Towards a global definition of patient centred care. BMJ. 2001;322(7284):444-445.

15. Mead N, Bower P. Patient-centredness: a conceptual framework and review of the empirical literature. Soc Sci Med. 2000;51(7):1087-1110.

16. Street R. Communication in Medical Encounters: An Ecological Perspective. In: Thompson T, Dorsey A, Miller K, Parrott R, eds. Handbook of Health Communication. London, UK: Lawrence Erlbaum Associates; 2003:63-89.

17. Borrell-Carrio F, Epstein RM. Preventing errors in clinical practice: a call for self-awareness. Ann Fam Med. 2004;2(4):310-316.

18. Brown J, Stewart M, Ryan B. Assessing Communication Between Patients and Physicians: The Measure of Patient-Centered Communication (MPCC). Working Paper Series, Paper \# 95-2, Second Edition. London, Ontarioa: Thames Valley Family Practice Research Unit and Centre for Studies in Family Medicine; 2001.

19. Fiscella K, Meldrum S, Franks $P$, et al. Patient trust: is it related to patient-centered behavior of primary care physicians? Med Care. 2004;42(11):1049-1055.
20. Stewart M, Brown JB, Donner A, et al. The impact of patient-centered care on outcomes. J Fam Pract. 2000;49(9):796-804.

21. Street RL Jr, Krupat E, Bell RA, Kravitz RL, Haidet P. Beliefs about control in the physician-patient relationship: effect on communication in medical encounters. J Gen Intern Med. 2003;18(8):609-616.

22. Street R. Active patients as powerful communicators. In: Robinson W, Giles H, eds. The New Handbook of Language and Social Psychology. New York, NY: John Wiley \& Sons; 2001:541-560.

23. Nendaz MR, Bordage G. Promoting diagnostic problem representation. Med Educ. 2002;36(8):760-766.

24. Charlin B, Roy L, Brailovsky C, Goulet F, van der Vleuten C. The Script Concordance test: a tool to assess the reflective clinician. Teach Learn Med. 2000;12(4):189-195.

25. Bordage G. Elaborated knowledge: a key to successful diagnostic thinking. Acad Med. 1994;69(11):883-885.

26. Gerrity MS, White KP, Devellis RF, Dittus R. Physicians' reactions to uncertainty: refining the constructs and scales. Motivation and Emotion. 1995:19:175-191.

27. Epstein RM. Mindful practice. JAMA. 1999;282(9):833-839.

28. Seaburn DB, Morse D, McDaniel SH, et al. Physician responses to ambiguous patient symptoms. J Gen Intern Med. 2005;20(6):525-530.

29. Krupat E, Bell RA, Kravitz RL, Thom D, Azari R. When physicians and patients think alike: patient-centered beliefs and their impact on satisfaction and trust. J Fam Pract. 2001;50(12):1057-1062.

30. Mead N, Bower P, Hann M. The impact of general practitioners' patient-centredness on patients' post-consultation satisfaction and enablement. Soc Sci Med. 2002;55(2):283-299.

31. Dugdale DC, Epstein R, Pantilat SZ. Time and the patient-physician relationship. J Gen Intern Med. 1999;14(Suppl 1):S34-S40.

32. Hall JA, Roter DL, Milburn MA, Daltroy LH. Patients' health as a predictor of physician and patient behavior in medical visits. A synthesis of four studies. Med Care. 1996;34(12):1205-1218.

33. Hall JA, Epstein AM, DeCiantis ML, McNeil BJ. Physicians' liking for their patients: more evidence for the role of affect in medical care. Health Psychol. 1993;12(2):140-146.

34. Ring A, Dowrick C, Humphris G, Salmon P. Do patients with unexplained physical symptoms pressurise general practitioners for somatic treatment? A qualitative study. BMJ. 2004;328(7447):1057.

35. Roter DL, Stewart M, Putnam SM, et al. Communication patterns of primary care physicians. JAMA. 1997;277(4):350-356

36. Bertakis KD, Callahan EJ. A comparison of initial and established patient encounters using the Davis Observation Code. Fam Med. 1992;24(4):307-311.

37. Tamblyn RM, Abrahamowicz M, Berkson L, et al. First-visit bias in the measurement of clinical competence with standardized patients. Acad Med. 1992;67(10 Suppl):S22-24.

38. Franz CE, Epstein R, Miller KN, Brown A, Song J, Feldman M, Franks P, Kelly-Reif S, Kravitz RL. Caught in the act? Prevalence, predictors, and consequences of physician detection of unannounced standardized patients. Health Serv Res. 2006;41(6):2290-2302.

39. Griffin SJ, Kinmonth AL, Veltman MW, et al. Effect on healthrelated outcomes of interventions to alter the interaction between patients and practitioners: a systematic review of trials. Ann Fam Med. 2004;2(6):595-608

40. Lewin S, Skea Z, Entwistle V, Dick J, Zwarenstein M. Interventions for Providers to Promote a Patient-Centered Approach in Clinical Consultations. Oxford, UK: Update Software; 2001.

41. Makoul G, Arntson P, Schofield T. Health promotion in primary care: physician-patient communication and decision making about prescription medications. Soc Sci Med. 1995;41(9):1241-1254.

42. Sleath B, Roter D, Chewning B, Svarstad B. Asking questions about medication: analysis of physician-patient interactions and physician perceptions. Med Care. 1999;37(11):1169-1173.

43. Borowsky SJ, Rubenstein LV, Meredith LS, et al. Who is at risk of nondetection of mental health problems in primary care? J Gen Intern Med. 2000;15(6):381-388. 